\title{
A IMPORTÂNCIA DA ESCOLA, ALUNO, ESTÁGIO SUPERVISIONADO E TODO O PROCESSO EDUCACIONAL NA FORMAÇÃO INICIAL DO PROFESSOR
}

\section{LA IMPORTANCIA DE LA ESCUELA DEL ESTUDIANTE , SUPERVISADO Y TODO PROCESO EDUCATIVO EN LA FORMACIÓN INICIAL DEL PROFESORADO}

\section{THE IMPORTANCE OF SCHOOL STUDENT, SUPERVISED AND ALL EDUCATIONAL PROCESS IN INITIAL TEACHER TRAINING}

\author{
Paulo Cássio Alves LINHARES ${ }^{1}$ \\ Toni Halan da Silva IRINEU ${ }^{2}$ \\ Josimar Nogueora da SILVA ${ }^{3}$ \\ Janailson Pereira de FIGUEREDO ${ }^{4}$ \\ Thiago Pereira de SOUSA ${ }^{5}$
}

\begin{abstract}
RESUMO: O Estágio Supervisionado é o primeiro contato que o aluno-professor tem com seu futuro campo de atuação. Com isto, esse trabalho visa relatar qual a importância da escola, aluno, professor, o estágio supervisionado e todo o processo educacional na formação inicial do professor. A escola tem a função de acolher as camadas populares, da mais pobre a mais rica, e difundir o conhecimento. A relação professor-aluno é uma condição do processo de aprendizagem, pois essa relação dinamiza e dá sentido ao processo educativo. O aluno vai percebendo que ele também é autor da história, visto que, de posse da compreensão do conhecimento, passa a entender melhor a sua realidade. O professor deve ter um papel de facilitador do processo de ensino aprendizagem junto ao aluno. Conclui-se que houve mudança no papel do professor e também do aluno.
\end{abstract}

Palavras-chave: escola; sala de aula; aluno; estágio; educação.

RESUMEN: Supervisado Internship es el primer contacto que el estudiante - maestro tiene con su campo de futuro. Por lo tanto, este trabajo se describe la importancia de la escuela, estudiante, profesor, entrenamiento supervisado y todo el proceso educativo en la formación inicial del profesorado. La escuela sirve para dar cabida a las clases trabajadoras, a los más pobres a los más ricos, y difundir el conocimiento. La relación profesor-alumno es una condición del proceso de aprendizaje, porque esta relación agiliza y da sentido al proceso

\footnotetext{
${ }^{1}$ Mestrando em Fitotecnia. Programa de Pós-graduação em Fitotecnia. Departamento de Ciências Vegetais.

Universidade Federal Rural do Semi-Árido - UFERSA. paulo_linhares2011 @ hotmail.com

2 Universidade Federal da Paraíba - UFPB. tonnysilva_oliveira@ hotmail.com

3 Mestrando em Fitotecnia. Programa de Pós-graduação em Fitotecnia. Departamento de Ciências Vegetais. Universidade Federal Rural do Semi-Árido - UFERSA. josimar2160@ hotmail.com

${ }^{4}$ Mestrando em Agronomia. Universidade Federal da Paraíba - UFPB. janailsondfigueredo@ hotmail.com

5 Mestrando em Fitotecnia. Programa de Pós-graduação em Fitotecnia. Departamento de Ciências Vegetais. Universidade Federal Rural do Semi-Árido - UFERSA. tiagojd2009@ hotmail.com
} 
educativo El estudiante se dará cuenta de que él también es el autor de la historia, ya que la posesión de la comprensión de los conocimientos, los pases comprender mejor su realidad. El maestro debe ser un facilitador del proceso de enseñanza-aprendizaje con el estudiante. Llegamos a la conclusión de que hubo un cambio en el papel del profesor y el estudiante también.

Palabras clave: escuela; el salón de clases; estudiante; etapa; la educación.

\begin{abstract}
The Supervised Internship is the first contact that the student - teacher has with his future field. Hence, this paper describes how important school, student, teacher, supervised training and the entire educational process in initial teacher training. The school serves to accommodate the working classes, the poorest to the richest, and disseminate knowledge. The teacher-student relationship is a condition of the learning process, because this relationship streamlines and gives meaning to the educational process. The student will realize that he is also the author of the story, since the possession of understanding of knowledge, passes better understand their reality. The teacher should be a facilitator of the teaching learning process with the student. We conclude that there was a change in the role of the teacher and the student also.
\end{abstract}

Keywords: school; classroom; student; training; education.

\title{
Introdução
}

O Estágio Supervisionado é o primeiro contato que o aluno-professor tem com seu futuro campo de atuação. Onde, por meio da observação, da participação e da regência, o licenciando poderá refletir sobre e vislumbrar futuras ações pedagógicas. Assim, sua formação tornar-se-á mais significativa quando essas experiências forem socializadas em sua sala de aula com seus colegas, produzindo discussão, possibilitando uma reflexão crítica, construindo a sua identidade e lançando, dessa forma, "um novo olhar sobre o ensino, a aprendizagem [e] a função do educador" (PASSERINI, 2007).

Caracterizando-se como objeto de estudo e reflexão, o Estágio Supervisionado poderá ser um agente contribuidor na formação do professor. Ao estagiar, o futuro professor passa a enxergar a educação com outro olhar, procurando entender a realidade da escola e o comportamento dos alunos, dos professores e dos profissionais que a compõem. Com isso faz uma nova leitura do ambiente (escola, sala de aula, comunidade), procurando meios para intervir positivamente (JANUARIO, 2008).

Para Pimenta (2005), todos os alunos e professores entendem o estágio como uma atividade que traz os elementos da prática para serem objeto de reflexão, de discursão, e que 
propicia um conhecimento da realidade na qual irão atuar. Por isso, consideram-no importante, á exceção de um professor para quem "tanto o estágio quanto a oficina são artificiais - mesmo que aprimorados não são a realidade".

Neste aspecto, ao iniciar uma licenciatura, muitas vezes vem à insegurança e o receio de não desenvolver um bom trabalho em sala de aula. Alguns temem não conseguir dominar a classe, outros se preocupam em não saber todo o conteúdo que julgam necessário, uns questionam-se quanto ao método que adotarão e outros, ainda, anseiam por ministrar aulas. Há ainda uns que se quer pensam em lecionar (JANUARIO, 2008).

Indivíduos que não atuam no interior da escola possuem conhecimentos superficiais da realidade escolar. Sendo que, o estágio amparado a uma fundamentação teórica, propiciará aos futuros professores um entendimento mais claro das situações ocorridas no interior das escolas e, consequentemente, possibilitará uma adequada intervenção da realidade (PELOZO, 2007).

Assim sendo, o estágio é um meio que pode levar o acadêmico a identificar novas e variadas estratégias para solucionar problemas que muitas vezes ele nem imaginava encontrar na sua área profissional. Ele passa a desenvolver mais o raciocínio, a capacidade e o espírito crítico, além da liberdade do uso da criatividade (ROSSI, 2012).

Segundo Barreto (2006), o Estágio de Licenciatura é uma exigência da Lei de Diretrizes e Bases da Educação Nacional (n 9394/96). No qual, é necessário à formação profissional a fim de adequar essa formação às expectativas do mercado de trabalho onde o licenciado irá atuar. Assim o estágio dá oportunidade de aliar a teoria à prática.

Nesse enfoque, esse trabalho visa relatar qual a importância da escola, aluno, professor, o estágio supervisionado e todo o processo educacional na formação inicial do professor.

\section{A função da escola}

A escola tem a função de acolher as camadas populares, da mais pobre a mais rica, e difundir o conhecimento, de modo, que todos tenham formação de social e técnico-científica, levando ao sujeito uma formação status, baseando-se em novas culturas (LIBÂNEO, 2009).

Onde, garantir a aprendizagem de conhecimentos, habilidades e valores necessários à socialização do indivíduo, é a função básica da escola. Estas aprendizagens devem construirse em instrumentos para que o aluno compreenda melhor a realidade que o cerca, favorecendo sua participação em relações sociais cada vez mais amplas, possibilitando a leitura e 
interpretação das mensagens e informações que hoje são amplamente veiculadas, preparandoo para a inserção no mundo do trabalho e para a intervenção critica e consciente na vida pública.

Abondanza (2002), destaca:

"no processo ensino-aprendizagem, a escola não apresenta condições de reproduzir exatamente as situações e a organização da vida técnica e econômica. Compete sim à escola, dotar o indivíduo de uma formação técnica e a de cultivar e desenvolver a cultura profissional".

Consideravelmente, é isso que a escola deve proporcionar ao aluno e a sociedade de forma geral, pois a escola deve formar o cidadão para a sociedade, tornando um ser pensante capaz de melhorar o mundo contemporâneo.

Pois, a escola dos sonhos é aquela que assegura a todos a formação cultural científica para a vida pessoal, profissional e cidadã, possibilitando uma relação autônoma, crítica e construtiva com a cultura e suas várias manifestações (BARBOSA \& CALIL, 2002).

Portanto, a escola tem como compromisso social de ir além da simples transmissão do conhecimento sistematizado, preocupando-se em dotar o aluno da capacidade de buscar informações segundo as exigências de seu campo profissional ou de acordo com as necessidades de desenvolvimento individual e social.

\section{O espaço sala de aula - escola}

O espaço da sala de aula é um lugar privilegiado, onde se encontram professores e alunos que participam de ambientes sociais diversificados que necessitam estabelecer uma convivência, acredita-se ainda que;

[...] a sala de aula é o lugar em que há uma reunião de seres pensantes que compartilham ideias, trocam experiências, contam histórias, enfrentam desafios, rompem com o velho, buscam o novo, enfim, há pessoas que trazem e carregam consigo saberes cotidianos que foram internalizados durante sua trajetória de vida, saberes esses que precisam ser rompidos para dar lugar a novos saberes (VASCONCELLOS, 1993).

Assim, a responsabilidade da escola é imensa, o encaminhamento dado às questões pedagógicas e não pedagógicas que surgem no seu dia-a-dia, principalmente na sala de aula 
assume um importante significado na formação dos sujeitos, na construção de seus conceitos e concepções. Na qual, o desafio de enfrentar os problemas decorrentes das diferenças e da pluralidade cultural, social, étnica, entre outras, é cada vez mais patente no processo educativo e não pode ser silenciado.

Segundo Maturana (1999), as relações humanas que não se baseiam na aceitação do outro como um legítimo outro na convivência não são relações sociais. O mesmo diz ainda que, qualquer tipo de preconceito seja social, racial, religioso ou de gênero, deve ser questionado, criticado e banido do espaço escolar se quisermos educar para a aceitação e o respeito de si mesmo, que leva à aceitação e ao respeito do outro, para a reconstrução de uma sociedade mais justa e fraterna.

No cotidiano da sala de aula, essas situações de conflito aluno/aluno, aluno/professor são muito comuns; sendo decorrentes de fatores diversos. Nesses momentos, a afetividade é intensa, há um misto de irritação e medo e as crises emocionais são frequentes, gerando muitas vezes, o descontrole e a redução do nível de discernimento para a resolução dos mesmos. Assim, a emoção só será compatível com os interesses e a segurança do indivíduo se souber se compuser com o conhecimento e o raciocínio - seus sucessos -, ou seja, se em parte, deixar-se reduzir (WALLON apud ALMEIDA, 2001).

Para Perrenoud (2000), a escola passa a ser um lugar onde o educando tem direito a ensaios e erros, onde expõe suas dúvidas, explicita seus raciocínios e toma consciência de como se aprende, permitindo tornar visíveis os processos, os ritmos e os modos de pensar e de agir. Com isto, a aprendizagem inclui projetos de situações problema, que fazem com que o aluno participe em um esforço coletivo para elaborar um projeto e construir novas competências.

\section{A relação professor-aluno}

A relação professor-aluno é muito importante, a ponto de estabelecer posicionamentos pessoais em relação à metodologia, à avaliação e aos conteúdos (AQUINO, 1996). Se a relação entre ambos for positiva, a probabilidade de um maior aprendizado aumenta. Com isso, a força da relação professor-aluno é significativa e acaba produzindo resultados variados nos indivíduos.

Esta relação é uma condição do processo de aprendizagem, pois a mesma dinamiza e dá sentido ao processo educativo. Em que, apesar de estar sujeita a um programa, normas da 
instituição de ensino, a interação do professor e do aluno forma o centro do processo educativo. Apesar disso, pode se mostrar conflituosa, pois se baseia no convívio de classes sociais, culturas, valores e objetivos diferentes. No entanto, podem se observar dois aspectos da interação professor-aluno: o aspecto da transmissão de conhecimento e a própria relação pessoal entre professor e aluno e as normas disciplinares impostas. Na qual, essa relação deve estar baseada na confiança, afetividade e respeito, cabendo ao professor orientar o aluno para seu crescimento interno, isto é, fortalecer-lhe as bases morais e críticas, não deixando sua atenção voltada apenas para o conteúdo a ser dado (MÜLLER, 2002).

Segundo Freire (2007), o ideal são professores sem receio de expressar sua afetuosidade, "é preciso não ter medo do carinho [...]. Só os mal-amados e as mal-amadas entendem a atividade docente como um quefazer de insensíveis, de tal maneira cheios de racionalismo que se esvaziam de vida e de sentimentos".

O espaço destinado à construção do conhecimento deve ser um referencial de aspectos positivos e motivadores. Em que, cada um dos presentes na sala de aula tem uma história que será modificada a partir das experimentações que ocorreram ao longo de sua existência e convivência estudantil. Ideia esta, que Guebert (2008), afirma,

É de suma importância destacar que todo processo de construção precisa de uma referência. Neste caso professora-educadora, é uma profissional responsável por ser esta referência, logo sua comunicação verbal, gestual, sua observação e seu desejo de contribuir devem ser intensos. Portanto este estilo da professora-educadora que influencia o desenvolvimento cognitivo e linguístico das crianças e, por outro lado, a interação entre elas, influencia também o estilo comunicativo da própria professora educadora (GUEBERT, 2008).

\section{O Papel do Aluno}

Considerando o processo educacional, é bom lembrar que, a responsabilidade não se enquadra mais somente encima do educador. Nesta perspectiva, alguns educadores, considerados mais conservadores, devem repensar suas ações, reorganizar-se, mudar sua forma de agir e sua visão do papel do aluno no processo educativo.

De acordo com Pilão (1998), não se deve pensar que o aluno deva ser deixado em total liberdade para fazer o que bem entender, sendo o professor relegado à posição de mero 
observador e não de interventor da aprendizagem, devido ao fato de ser considerado o centro do processo educativo.

Noutro momento, ocorre a Catarse, onde se compreende que aqui o aluno é capaz de apresentar um posicionamento mais elaborado da Prática Social, integrando os conhecimentos que já conhecia com os científicos. Considera-se que esse é o momento de apropriação do conteúdo.

Para Gasparin (2005), no momento da Catarse social feita com base em necessidades criadas pelo homem, o conhecimento possui uma função explícita: a transformação social.

Deste modo, o aluno vai percebendo que ele também é autor da história, visto que, de posse da compreensão do conhecimento, passa a entender melhor a sua realidade.

\section{O papel do professor}

O professor deve ter um papel de facilitador do processo de ensino aprendizagem junto ao aluno, em todo o contexto no qual ele está inserido, e estar em constante atualização de conhecimentos mediante as mudanças que ocorrem no mundo globalizado de hoje.

De acordo com Queiroz (2001) “o papel do professor é fazer que os alunos adquiram certos saberes, presentes, em geral, nas matérias escolares, participando, além disso, da educação no sentido mais amplo, preparando-o para a vida em sociedade”. Pimenta \& Lima (2004), afirmam que "o professor é um profissional que ajuda o desenvolvimento pessoal e intersubjetivo do aluno, sendo um facilitador de seu acesso ao conhecimento".

No entanto, o professor precisa ter consciência da importância de sua função. Ele não pode perder a dimensão de que a escola é o lugar da ampliação da experiência humana, o lugar onde se constrói conhecimento, com o uso das diversas linguagens e imaginação. Porém, tudo isso só poderá ocorrer com o seu "saber fazer", daí a importância da sua formação continuada, pois,

O professor, responsável direto pelo cotidiano da sala de aula, apresenta-se, então, como mais ou menos qualificado para exercer sua função, com maior ou menor autonomia e controle sobre o seu processo de trabalho (ENGUITA, 1989).

Para Barbosa \& Calil (2002), o professor precisa antes de tudo, ser um pensador reflexivo sugerindo um caminho didático para a sua autoafirmação como educador pósmoderno, onde estejam inseridos os desafios dos conceitos e estruturas administrativas da 
escola, com objetivo de inovar os padrões já estabelecidos e promover um "fazer" diferente, onde a reflexão, a crítica e as criatividades sejam permanentes.

Os mesmos ainda afirmam, que o professor pode proporcionar ao aluno, buscar o caminho para sua própria construção de um saber mais elaborado, uma maneira mais simples de olhar a realidade, procurando superar dificuldades encontradas em sua trajetória, para alcançar bom desempenho no processo ensino aprendizagem. Mas para que isto aconteça é importante que o professor tenha consciência de que uma de suas funções é organizar, para o aluno, sua relação com o meio, criando situações que o levem a construir seu próprio conhecimento, partindo das ideias e saberes que o aluno já possui, valorizando e respeitando suas contribuições e estimulando um processo autônomo de aprendizagem.

Quando o professor pergunta, ele não está simplesmente querendo obter respostas que já conhece, pois incentivar o pensamento filosófico é querer que o educando reflita de maneira nova, considere métodos alternativos de pensar e agir. Neste ponto, devemos observar o que foi escrito por Libâneo (1994):

“O professor não apenas transmite uma informação ou faz perguntas, mas também ouve os alunos. Deve dar-lhes atenção e cuidar para que aprendam a expressar-se, a expor opiniões e dar respostas. $\mathrm{O}$ trabalho docente nunca é unidirecional. As respostas e opiniões mostram como eles estão reagindo à atuação do professor, às dificuldades que encontram na assimilação dos conhecimentos. Servem, também, para diagnosticar as causas que dão origem a essas dificuldades."

"O professor precisa ser um aprendiz ativo e cético na sala de aula, que convida os alunos a serem curiosos e críticos... e criativos" (FREIRE, 2007).

\section{O que é estágio supervisionado?}

O Estágio Supervisionado visa fortalecer a relação teoria e prática baseado no princípio metodológico de que o desenvolvimento de competências profissionais implica em utilizar conhecimentos adquiridos, quer na vida acadêmica quer na vida profissional e pessoal. Sendo assim, o estágio constitui-se em importante instrumento de conhecimento e de integração do aluno na realidade social, econômica e do trabalho em sua área profissional (BARRETO, 2006). 
Para Cabral \& Angelo (2010), o Estágio Supervisionado é a exteriorização do aprendizado acadêmico fora dos limites da universidade. É o espaço onde o licenciando irá desenvolver seus conhecimentos junto às instituições públicas e privadas, integrando a teoria e a prática, contribuindo para uma análise de pontos fortes e fracos das organizações e propondo melhorias para as instituições.

Segundo Piconez (2006); o estágio supervisionado ajuda ao aluno estagiário a entender na pratica qual será sua área de atuação, é uma forma de ajuntar a teoria à prática, formulando sua consciência política e social. Apresenta-se como uma forma de trocar ideias e possibilidades, para mudanças no modo de ensinar, do professor como aluno estagiário, que tem visão nova e abrangente da sociedade.

Segundo Andrade (2005),

o estágio é uma importante parte integradora do currículo, a parte em que o licenciado vai assumir pela primeira vez a sua identidade profissional e sentir na pele o compromisso com o aluno, com sua família, com sua comunidade com a instituição escolar que representa sua inclusão civilizatória, com a produção conjunta de significados em sala de aula, com a democracia, com o sentido de profissionalismo que implique competência-fazer bem o que lhe compete.

O Estágio Curricular Supervisionado é caracterizado por uma atividade didática pedagógica de ordem social, que proporciona ao aluno a participação em situações reais, em que este terá a oportunidade de desenvolver um trabalho relacionado com sua futura profissão. Portanto, o mesmo, é uma porta de entrada para o futuro profissional (BUENO, 2011).

Com isto, o fato de o estágio ser supervisionado por um docente o torna um treinamento, uma forma de profissionalização, na qual o estudante vivenciará o que tem aprendido na universidade, pois passa a perceber como os conteúdos são assimilados e podem ser úteis na prática e ajudar a eliminar as falhas existentes. É ainda, uma ferramenta que pode fazer a diferença para aqueles que estão adentrando o mundo do trabalho e que têm o poder de mudar a lamentável realidade da educação brasileira então observada (ROSSI, 2002). 


\section{O estágio supervisionado na formação inicial do professor}

A Formação de Professores é uma oportunidade que o professor volta a refletir sobre seus conceitos e teorias usando a sua própria experiência seguida de sua prática pedagógica (ELIA, 1995). Porém para Houssaye (1997) citado por Rodrigues (2013), a especificidade de uma formação pedagógica, seja inicial ou contínua, não é de refletir no que vamos fazer, nem no que devemos fazer, mas refletir no que fizemos. "A Formação Inicial de professores apresenta duas macros dimensões: uma responsável por rigorosa formação científica e a outra responsável por imersão exigente apoiada no contexto real de trabalho" (RODRIGUES, 2013). Este ainda cita que "a profissão de professor se aprende na escola e na sala de aula e é um processo longo de uma vida".

O Estágio Supervisionado na formação de professores tem sido alvo de grandes estudos que revelam suas dificuldades e seu potencial, gerando transformações na vida desses profissionais. "O estágio é o eixo central na formação de professores, pois é através dele que o profissional conhece os aspectos indispensáveis para a formação da construção da identidade e dos saberes do dia-a-dia" (PIMENTA \& LIMA, 2004).

Januário (2008), diz que, o futuro professor, ao estagiar passa a ter uma nova visão sobre educação, levantando-se a procurar novos meio de intervir sobre o ambiente escolar, sala de aula e sociedade. Dessa forma, o estágio supervisionado é considerado como objetivo de estudo e reflexão da formação do educador.

Com isto, a experiência do estágio é essencial para a formação integral do aluno, considerando que cada vez mais são requisitados profissionais com habilidades e bem preparados. Pois, ao chegar à universidade o aluno se depara com o conhecimento teórico, porém muitas vezes, é difícil relacionar teoria e prática se o estudante não vivenciar momentos reais em que será preciso analisar o cotidiano (MAFUANI, 2011).

Destaca ainda, que o Estágio Supervisionado baseia-se em um treinamento que possibilita aos estudantes vivenciarem o que aprenderam durante a graduação. Na qual, os cursos de Licenciatura devem relacionar teoria e prática de forma interdisciplinar, sendo que os componentes curriculares não podem ser isolados. Por isso, o Estágio Supervisionado é considerado um elo entre o conhecimento construído durante a vida acadêmica e a experiência real, que os discentes terão em sala de aula quando profissionais (FILHO, 2010).

Deste modo, tanto o aprender a profissão docente quanto dar continuidade a mesma faz parte do cotidiano do professor. É dessa forma que o profissional conseguirá sempre fazer a 
ligação entre teoria e prática (FILHO, 2010). Com isso fica clara a importância desta atividade, que traz imensos benefícios para a aprendizagem, para a melhoria do ensino e principalmente para o estagiário. Sendo que os maiores beneficiados será a sociedade e, em especial, a comunidade a que se destinam os profissionais egressos da universidade (BIANCHI, 1998).

\section{Considerações finais}

O estágio supervisionado é sem via das dúvidas a ferramenta ideal para o início da operação a ser realizada pelo profissional aprendiz de um curso de Licenciatura, ou seja, o aluno estagiário que será um futuro professor. É um instrumento de aquisição de uma nova realidade, pois vivenciamos novas experiências que nos mostram a realidade da nossa futura profissão, através de uma forma mais técnica e profissional.

Conclui-se que houve mudança no papel do professor e também do aluno. O professor deve ter como função estimular amplamente a busca de novos conhecimentos, ou seja, está atualizado e reciclado de acordo com as mudanças tecnológicas, sociais, culturais, econômicas e políticas. Percebe-se que a formação do professor também deixa muito a desejar. O educador não está preparado para esses novos tempos.

Há de confirmar que muita coisa mudou, mas não o bastante. Existem dificuldades para colocar em prática as novas concepções e os novos modelos. É preciso estar aberto às novidades e procurar diferentes métodos de trabalho, mas sempre partindo de uma análise individual e coletiva das práticas.

\section{Referências bibliográficas}

ABONANZA, I. Estágio Supervisionado: obrigação ou motivação. Revista Brasileira de Administração. Brasília, Ano XII, n. 36, p.18-23. 2002.

ALMEIDA, A. R. S. A emoção na sala de aula. São Paulo: Papirus, 2001.

ANDRADE, A. M. O Estágio Supervisionado e a Práxis. 2005, p.2. Disponível em:<WWW.educ.ufrn.br/arnon/estagio.pdf $>$. Acesso em: 19/08/2013.

AQUINO, J. G. A relação professor-aluno: do pedagógico ao institucional. São Paulo: Summus, 1996. 
BARBOSA, E. G. \& CALIL, R. C. Formação do professor: a técnica do saber Fazer. Trabalho de Conclusão de Curso (Licenciado em Pedagogia). Belém: UNAMA, 2002.

BARRETO, C. S. Relatório do Estágio Supervisionado I. Relatório de Estágio apresentado ao Curso de Licenciatura em Matemática como parte da exigência da disciplina Estágio Supervisionado I. Vitória da Conquista - BA, 2006.

BIANCHI, A. C. M. Manual de Orientação: Estágio Supervisionado. São Paulo: Pioneira, 1998.

BUENO, G. D. R. Estágio supervisionado: compromisso na formação. Anais... X Congresso Nacional de Educação - EDUCERE e I SEMINÁRIO INTERNACIONAL DE REPRESENTAÇÕES SOCIAIS, SUBJETIVIDADE E EDUCAÇÃO-SRSSE. Curitiba, 7 a 10 de novembro de 2011.

CABRAL, V. L. A. \& ANGELO, C. B. Reflexões sobre a importância do estágio supervisionado na prática docente. VI EPBEM - Monteiro, PB - 09, 10 e 11 de novembro de 2010. Disponível em: <www.sbempb.com.br/epbem> Acesso em: 26/08/2013.

ELIA, M. A formação de Professores na UFRJ: Uma visão Institucional, 1995. Disponível em: 〈http:www.cciencia.Ufrj.br/Publicacoes/Artigos/Edubytes95/FormProfUFRJ.htm> Acesso em 25 Nov. 2013.

ENGUITA, M. F. A face oculta da escola. Porto Alegre: Artes Médicas, 1989.

FILHO, A. P. O Estágio Supervisionado e sua importância na formação docente. Revista P@rtes. 2010. Disponível em:

<http://www.partes.com.br/educacao/estagiosupervisionado.asp>. Acesso em: 19/08/2013.

FREIRE, P. Educação e mudança. 30ª ed. Rio de Janeiro: Paz e Terra, 2007.

GASPARIN, J. L. Uma didática para a pedagogia histórico-crítica. 3 ed. Campinas: Autores Associados, 2005.

GUEBERT, M. C. C. A identidade e autonomia em crianças de 0 a 5 anos: Abordagem sistêmica. Curitiba: Pro-Infantil, 2008.

HOUSSAYE, J. "Spécificité et dénégation de la pédagogie". Révue Française de Pédagogie, 120, pp. 82-97, 1997.

JANUÁRIO, G. O Estagio supervisionado e suas contribuições para a prática pedagógica do professor. In: SEMINÁRIO DE HISTORIA E INUESTIGAÇÕES DE/EM AULAS DE MATEMATICA, 2, 2008, Campinas. Anais: II SHIAM. Campinas: GPS/FE - Unicamp; 2008. V. Único. P.1-8.

LIBÂNEO, J. C. A pedagogia critica-social dos conteúdos. In: Democratização da escola publica. 23. Ed. São Paulo: EDIÇÕES LOYOLA, 2009.

LIBÂNEO, J. C. Didática. São Paulo: Cortez Editora, 1994. 
MAFUANI, F. Estágio e sua importância para a formação do universitário. Instituto de Ensino superior de Bauru. 2011. Disponível em:

$<$ http://www.iesbpreve.com.br/base.asp?pag=noticiaintegra.asp\&IDNoticia=1259> Acesso em: 19/08/2013.

MATURANA, H. Emoções e Linguagem na Educação e na Política. Belo Horizonte: UFMG, 1999.

MÜLLER, L. S. A interação professor - aluno no processo educativo. INTEGRAÇÃO: Ensino-pesquisa-extensão, Ano VIII, nº 31, p. 276-280, Novembro/2002.

PASSERINI, G. A. O estágio supervisionado na formação inicial de professores de matemática na ótica de estudantes do curso de licenciatura em matemática da UEL. 121f. Dissertação (Mestrado em Ensino de Ciências e Educação Matemática) - Universidade Estadual de Londrina. Londrina: UEL, 2007.

PELOZO, R. C. B. Prática de Ensino e o Estágio Supervisionado enquanto mediação entre ensino, pesquisa e extensão. REVISTA CIENTÍFICA ELETÔNICA DE PEDÁGOGIA. Ano V, $n^{\circ}$ 10, 2007.

PERRENOUD, P. Dez novas competências para ensinar. Porto Alegre: Artes Médicas Sul, 2000 .

PICONEZ, S. C. B; FAZENDA, I. C. A. A prática de ensino e estagio supervisionado. $12^{\text {a }}$ ed. Campinas. SP: Papirus, 2006.

PILÃO, J. M. O Construtivismo. São Paulo: Edições Loyola, 1998.

PIMENTA, S. G. O Estágio na Formação de Professores: Unidade Teoria e Prática? 6. ed. São Paulo: Cortez, 2005.

PIMENTA, S. G.; LIMA, M. S. L. Estágio e Docência. 2. ed. São Paulo: Cortez, 2004.

QUEIROZ, G. R. P. C. Processo de Formação de Professores Artistas Reflexivos de Física. Revista Cedes. Campinas, v. 22, n.74, p. 97-119, Abril, 2001.

RODRIGUES, A. A Formação de Formadores para a prática na Formação Inicial de professores. Disponível em: 〈http://www.educ.fc.ul.pt/recentes/mpfip/pdfs/arodrigues.pdf> Acesso em 25 Nov. 2013.

ROSSI, D. F. A importância do estágio supervisionado. São Paulo: ETEC de Tiquatira, 2012. Disponível em: < http://www.etectiquatira.com.br/estagio.pdf> Acesso em: 26/08/2013.

VASCONCELLOS, C. S. Construção do conhecimento em sala de aula. São Paulo: Salesiana Dom Bosco, 1993.

WALLON, H. Psicologia e Educação da Infância. Lisboa: Estampa, 1975. 